\title{
Experimenting on Natural Acid-Base Indicators: A Home-based Chemistry Activity during the COVID-19 Pandemic as evaluated by Teachers
}

\author{
Joje Mar P. Sanchez ${ }^{1,9 *}$, Melton James U. Fernandez ${ }^{2,10}$, Jules Mark O. Abgao ${ }^{3,10}$, Hezel H. \\ Sarona ${ }^{4,10}$, Stephen Bryan C. Asenjo ${ }^{5,10}$, Blezy V. Guiroy ${ }^{6,10}$, Abegail Joyce D. Oponda7,10, \\ Xerxen M. Vale 8,10 \\ ${ }^{1}$ College of Teacher Education, Cebu Normal University, Cebu City, Philippines 6000 \\ ${ }^{2}$ Senior High School Department, Asian College of Technology, Cebu City, Philippines 6000 \\ ${ }^{3}$ Chemistry Unit, Curriculum and Instruction Division, Philippine Science High School-Central Visayas Campus, \\ Argao, Cebu, Philippines 6021 \\ ${ }^{4} J u n i o r$ High School Department, Canduman National High School, Mandaue City, Philippines 6014 \\ 5 Junior High School Department, Dalaguete National High School, Dalaguete, Cebu Philippines 6022 \\ ${ }^{6} J u n i o r$ High School Department, City Central National High School, Cebu City, Philippines 6000 \\ ${ }^{7}$ Senior High School Department, University of Cebu- Banilad Campus, Cebu City, Philippines 6000 \\ ${ }^{8}$ Junior High School Department, Media Once National High School, Toledo City, Philippines 6038 \\ ${ }^{9}$ Graduate Faculty, Master of Education Program, University of the Philippines Cebu, Cebu City, Philippines \\ 6000 \\ ${ }^{10}$ M.Ed. Chemistry Program, University of the Philippines Cebu, Cebu City, Philippines 6000
}

*Author to whom correspondence should be addressed; email: sanchezj@cnu.edu.ph

\begin{abstract}
This study determined the feasibility of conducting a laboratory experiment on natural acid-base indicators as a home-based activity. Seven high school teachers from Cebu in Central Visayas, Philippines conducted the home-based activity, evaluated the activity using a validated questionnaire, and were interviewed for opportunities and challenges. Results showed that the at-home activity was feasible and satisfactory, however inaccuracies and inconsistencies were found in the results of the experiment. Nevertheless, the teachers viewed the experiment to have opportunities for holistic development and some challenges concerning material unavailability, safety issues, among others. In conclusion, the home-based activity can be done by students as evaluated by their teachers. Refinement of the activity may be done to correct experimental errors and consider factors that may affect the accuracy of the experimental results. Teachers should also consider resource availability, adult supervision, and safety concerns when dealing with home-based activities.
\end{abstract}

Keywords: home-based activity, natural acid-base indicators, feasibility 


\section{INTRODUCTION}

Chemistry plays an important role in developing the process skills of the students (Irwanto et al., 2017). Observation, measurement, hypothesis formulation, and results-based generalization are some process skills that students can develop during chemistry classes, particularly during laboratory experimentation. However, the conduct of laboratory experiments has become difficult due to the limitations caused by the COVID-19 pandemic. Despite the limitations, teachers continually find ways how to integrate experimentation in their remote/online classes. Some teachers perform the experiments as demonstrations for their classes and others, especially those coming from well-established private schools, hold laboratory activities in virtual laboratories. These means of conducting experimentation may be halted in modular mode of learning because of the almost total lack of teacher-student interactions. One way to not totally discount experimentation for any mode of learning is the conduct of home-based laboratory experiments.

Home-based laboratory experiments, also called home-based practical activities (Neves et al., 2017), practical science at home (Caruana et al., 2020), and at-home laboratories (Andrews et al., 2020), are carefully designed Chemistry activities intended for students to be done at home. In making these home-based activities, teachers should consider students' learning by themselves, the need for guidance and opportunity to use and develop skills (Neves et al., 2017), and the utilization of safe household materials without the need of special equipment (Andrews et al., 2020). With these considerations, teachers may formulate lab activities or contextualize experiments according to the lives of students, especially in challenging times during the COVID19 pandemic. This led the researchers to investigate the feasibility of conducting a home-based activity, particularly on natural acid-base indicators.

Natural acid-base indicators are $\mathrm{pH}$ indicators that come from natural sources such as leaves, flowers, or fruits of certain plants with pigments that can change color when reacted with certain substances (Bhise et al., 2014). Like the commercial indicators, the color changes determine the acidity or basicity of substances. Rose (Rosa setigera), gumamela (Hibiscus rosa-sinensis) and yellow bell (Allamanda cathartica) are some examples of natural indicators (Okoduwa et al., 2015). The color changes exhibited by rose, gumamela, and yellow bell extracts exemplify the possibility that plants found in the garden, backyard, or along the road could be utilized as sources of natural $\mathrm{pH}$ indicators. Hence, the conduct of an experiment utilizing plants found at home or the community can be a feasible activity to be done at home.

The study aimed to investigate the feasibility of conducting a laboratory activity on natural acidbase indicators that can be done at home. For this study, seven teachers participated in the study to conduct the home-based experiment and assess the activity whether students can do it by themselves at home. The results obtained from the conduct of home-based activity determined: (a) the level of feasibility of the experiment in terms of independent learning, resource availability, adult supervision, safety precautions, and satisfaction; (b) the accuracy of the respondents' answers based on their results on color, color changes, and $\mathrm{pH}$ values compared to standard values; and (c) the challenges, opportunities, and implications for remote teaching.

The outcomes of the study are significant because it offers valuable insights to remote/online teaching of Chemistry in the country. Teachers would be informed of the extent of possibility of using self-conducted experiments at home. Parents too would be informed of the extent of their supervision of these activities in their respective homes. The school administration would also be given insights on how to deliver practical activities during the pandemic. 


\section{METHODS}

Research Design, Locale and Participants. The study employed the descriptive research design to assess the feasibility of a laboratory experiment on natural acid-based indicators as homebased activity. In this descriptive design, seven teachers from different parts of Cebu in Central Visayas, Philippines, participated in the conduct of the experiments at home. These teachers are aged between 20-30 and mostly females (57\%). They are mostly graduates of physical sciences and currently studying Chemistry education in a state university in the same locale. They are also licensed professional teachers in DepEd and DOST schools; hence, they can conduct the experiments and give inputs whether the home-based activity is feasible for remote learning.

Details of the Home-based Experiment. The procedure of the home-based experiment was adapted and modified from Mapa et al. (1997).

Preparation of Standard Solutions. Firstly, preliminary calculations were done to achieve $0.1 \mathrm{M}$ concentrations from household materials muriatic acid $(\mathrm{HCl})$ and lye $(\mathrm{NaOH})$ as stock solutions. Then, the standard solutions were prepared using $0.1 M \mathrm{HCl}(\mathrm{pH} \mathrm{1}), 0.1 \mathrm{M} \mathrm{NaOH} \mathrm{(pH} \mathrm{13),} \mathrm{and}$ freshly boiled distilled water $(\mathrm{pH} 7)$ using the details in Figure 1. The $\mathrm{pH}$ values were predetermined as provided and validated by Mapa et al. (1997) using the specific combinations of the said stock solutions.

Starting solutions:

pH 7 - freshly boiled distilled $\mathrm{H}_{2} \mathrm{O} \quad$ pH $1-0.1 \mathrm{M} \mathrm{HCl} \quad$ pH $13-0.1 \mathrm{M} \mathrm{NaOH}$

Preparation the following standard solutions (by group) and their corresponding $\mathrm{pH}$

\begin{tabular}{|c|c|}
\hline $5 \mathrm{~mL} \mathrm{pH} 1+45 \mathrm{~mL}$ pH $7=\mathbf{p H ~} 2$ & $5 \mathrm{~mL}$ pH $13+45 \mathrm{~mL} \mathrm{pH} 7=\mathbf{p H} \mathbf{1 2}$ \\
\hline $5 \mathrm{~mL} \mathrm{pH} 2+45 \mathrm{~mL} \mathrm{pH} 7=\mathbf{p H ~} 3$ & $5 \mathrm{~mL} \mathrm{pH} 12+45 \mathrm{~mL} \mathrm{pH} 7=\mathbf{p H} \mathbf{1 1}$ \\
\hline $5 \mathrm{~mL} \mathrm{pH} 3+45 \mathrm{~mL} \mathrm{pH} 7=\mathbf{p H ~} 4$ & $5 \mathrm{~mL}$ pH $11+45 \mathrm{~mL} \mathrm{pH} 7=\mathbf{p H} \mathbf{1 0}$ \\
\hline $5 \mathrm{~mL} \mathrm{pH} 4+45 \mathrm{~mL} \mathrm{pH} 7=\mathbf{p H} \mathbf{5}$ & $5 \mathrm{~mL}$ pH $10+45 \mathrm{~mL}$ pH $7=\mathbf{p H} 9$ \\
\hline $5 \mathrm{~mL} \mathrm{pH} 5+45 \mathrm{~mL} \mathrm{pH} 7=\mathbf{p H} 6$ & $5 \mathrm{~mL} \mathrm{pH} 9+45 \mathrm{~mL} \mathrm{pH} 7=\mathbf{p H ~} 8$ \\
\hline
\end{tabular}

Figure 1. Details of the preparation of the standard solutions based on Mapa et al. (1997)

Preparation of the Natural Acid-base Indicators. The natural indicators were prepared using leaves (from cassava, Manihot esculenta), flowers (from piti-piti, Ruellia tuberosa), and fruits (from tomato, Solanum lycopersicum). About 10 pieces of cassava leaves, 13 pieces of piti-piti flowers, and 3 pieces of cherry tomato fruits were cut finely and put in the blender with $6 \mathrm{~mL}$, distilled water. The resulting colored solution was drained and transferred into reagent bottles for testing later.

Testing. For the testing, 2 drops of the natural indicators were added into the solution with $\mathrm{pH} 1$, $\mathrm{pH} 7$, and pH 13 to determine the general colors in acidic, neutral, and basic substances. The same procedure was done to $\mathrm{pH}$ 2-6 and $\mathrm{pH} \mathrm{8-12}$ and color changes were identified. The indicators were then tested to common household substances (baby powder, baking soda, bleach, calamansi (Philippine lime or calamondin orange), detergent solution, muriatic acid, shampoo, soda drink, or vinegar) to see if they can give the same $\mathrm{pH}$ characteristics or $\mathrm{pH}$ values as indicated in the household's product label. 
Data Gathering and Analysis. Conduct of the Home-based Experiment. The teachers were given informed consent, detailing the nature, purpose, benefits and risks, and voluntary participation in the study. The experiments were then performed by the teachers in their respective homes. In conducting the experiment, they were divided into three groups: Group $1(n=3)$, Group $2(n=2)$, and Group $3(n=2)$ who will be working on natural indicators from leaves, flowers, and fruits, respectively. They followed the procedures, recorded the observations, and took photos of the results.

Evaluation of the Experiment. After the conduct of the experiment, the teachers answered a validated survey Likert-scale questionnaire about the feasibility and their satisfaction towards the experiment, taking into consideration the ability of their students when the latter will do it in their respective homes. The tool consists of five parts, namely, independent learning, resource availability, adult supervision, safety considerations, and satisfactions. These are the same considerations stated by Neves et al. (2017) and Andrews et al. (2020) when doing home-based experiments.

Interview. The researchers conducted an unstructured interview to the high school teachers. The interview was about their experiences when conducting the experiments at home. Some of the questions in the interview ask the opportunities they had, the challenges they encountered, the things they did to address the said challenges, and the recommendations for teaching.

Data Analysis. The results from the evaluation were analyzed using means and standard deviations with corresponding qualitative descriptions. Moreover, the accuracy of the respondents' answer underwent content analysis wherein the answers were compared with one another and with the published data. Finally, the interview results were analyzed using thematic analysis wherein codes are grouped into themes.

\section{RESULTS AND DISCUSSION}

Feasibility and Satisfaction towards the Home-based Experiment. The results of the teachers' evaluation of the home-based experiment (with consideration of their students' situations) are presented in Table 1.

Table 1. Level of feasibility and satisfaction of teachers towards the experiment

\begin{tabular}{|l|r|r|r|l|}
\hline \multicolumn{1}{|c|}{ Aspect } & No. of items & Mean & SD & Description $^{\mathbf{1}}$ \\
\hline Independent learning & 9 & 4.37 & 0.28 & Very Feasible \\
\hline Resource availability & 8 & 3.89 & 0.60 & Feasible \\
\hline Adult supervision & 9 & 2.79 & 0.61 & Fairly feasible \\
\hline Safety considerations & 9 & 4.06 & 0.82 & Feasible \\
\hline Satisfaction & 11 & 4.52 & 0.45 & Very satisfactory \\
\hline
\end{tabular}

1 Legend: Very feasible/satisfactory (4.21-5.00), Feasible/satisfactory (3.41-4.20),

Fairly feasible/satisfactory (2.61-3.40), Less feasible/satisfactory (1.81-2.60),

Not feasible/satisfactory (1.00-1.80)

Based on Table 1, the independent learning aspect ( $\mu=4.37)$ makes the home-based experiment very feasible, indicating that in the experiment, teachers believed that students can exercise independent learning while they learn through the experiment by themselves. Resource availability $(\mu=3.89)$ and safety considerations $(\mu=4.06)$ contribute to the feasibility of the experiment, suggesting that the resources are often easily found at home and the safety concerns are addressed. However, the experiment is only fairly feasible when it comes with adult 
supervision ( $\mu=2.79$ ), signifying that the students still need the guidance of an adult (e. g. teacher, parent, guardian, etc.) to do certain steps in the experimental procedures. Overall, the homebased experiment was rated Very Satisfactory $(\mu=4.52)$ because teachers believe that the activity can deliver good learning experience even if students are only at home. Feasibility of the experiment due to independent learning, resource availability, and safety considerations is in coherence with the recommended criteria for at-home experiments as stipulated by Neves et al. (2017) and Andrews et al. (2020). Students have been shown to exhibit satisfaction with homebased experiments as they increase their connection to real-life, providing the conditions essential for improved students' interest in Chemistry (Gendjova, 2007).

Accuracy of Results from the Experiment. The characteristic colors of acidic (pH 1), neutral ( $\mathrm{pH}$ $7)$, and basic ( $\mathrm{pH} 13)$ substances when mixed with cassava, piti-piti, and tomato extracts are shown in Table 2.

Table 2. Characteristic colors of acid, neutral, and base in the natural indicators

\begin{tabular}{|c|c|c|c|c|c|}
\hline \multirow{2}{*}{$\begin{array}{c}\text { Plant } \\
\text { Part }\end{array}$} & \multirow{2}{*}{ Plant Extracts } & \multicolumn{4}{|c|}{ Characteristic Colors } \\
\cline { 4 - 6 } & & $\begin{array}{c}\text { Raw } \\
\text { Extract }\end{array}$ & $\begin{array}{c}\text { Extract in } \\
\text { Acid (pH 1) }\end{array}$ & $\begin{array}{c}\text { Extract in } \\
\text { Neutral (pH 7) }\end{array}$ & $\begin{array}{c}\text { Extract in } \\
\text { Base (pH 13) }\end{array}$ \\
\hline Leaves & Cassava, with water only & & & & \\
\hline Flowers & Piti-piti, with water only & & & & \\
\hline Fruits & Tomato, with water only & & & & \\
\hline
\end{tabular}

The original colors of the raw cassava, piti-piti, and tomato extracts are dark green, violet, and orange, respectively (Table 2). Results show that cassava leaf extracts as well as tomato fruit extracts became colorless when exposed to an acid while the piti-piti flower extracts became pink in the same substance. The cassava and piti-piti extracts showed tints of dark green when exposed to a neutral solution and a basic substance. Tomato extracts were colored light yellow when mixed with a neutral solution and tints of green and yellow green with a base. Compared with published data, the piti-piti plant shows similar results (Safitri et al., 2019) while tomato extracts present similar results with the acidic and neutral solution but not in $\mathrm{pH} 13$ (Mebane and Rybolt, 1985). Though reported by Vedad (2006) in her study's abstract, the researchers have not found any online accessible copy of the full-paper for the color description of cassava leaf indicator.

The color and color changes across $\mathrm{pH}$ levels from 1 to 13 due to the natural acid-base indicators are shown in Figures 2-4.

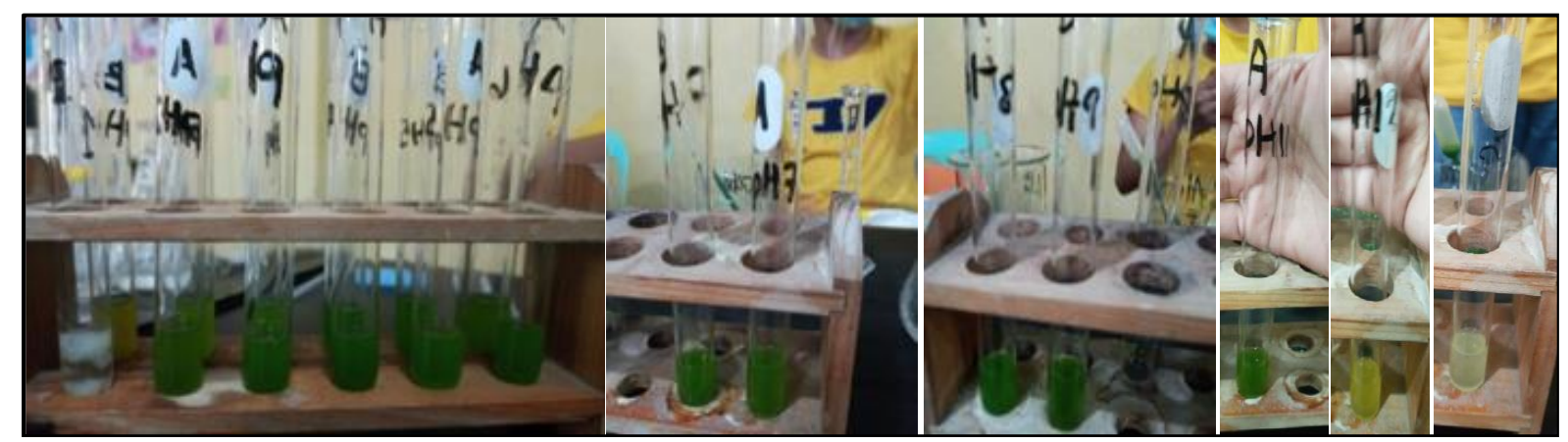

Figure 2. Color changes in cassava leaf extracts at $\mathrm{pH}$ 1-13 


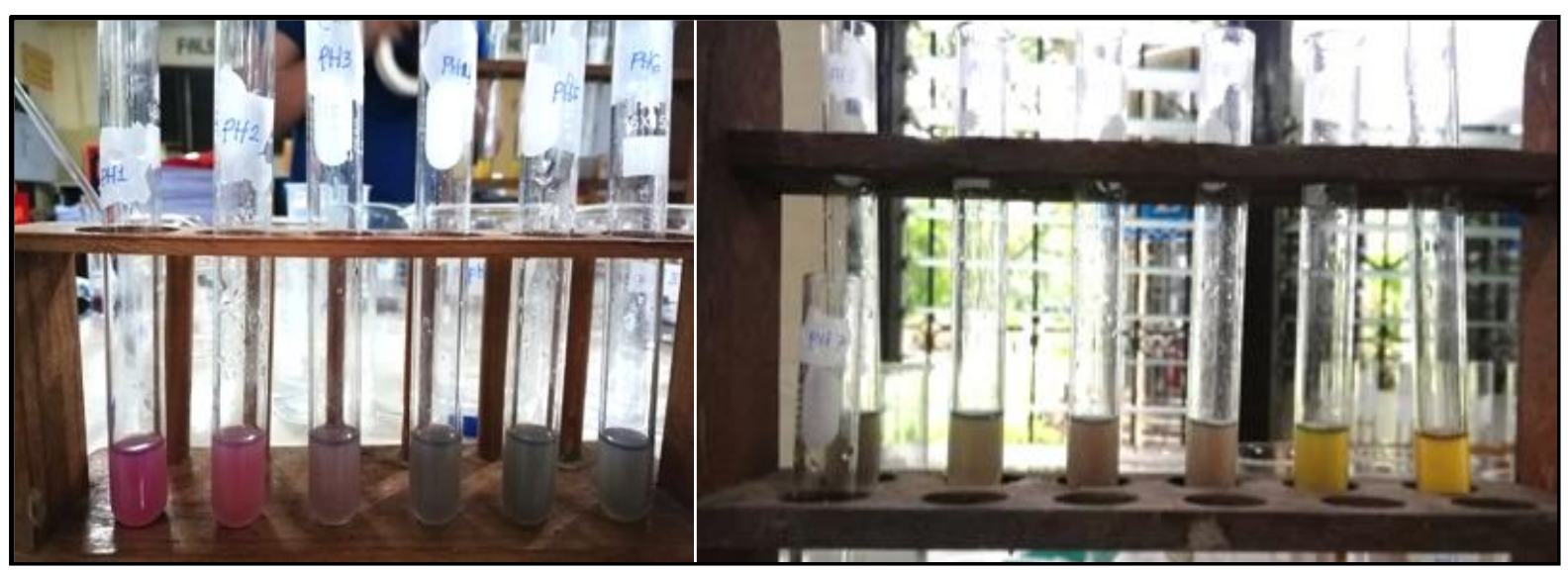

Figure 3. Color changes in piti-piti flower extracts at $\mathrm{pH}$ 1-13

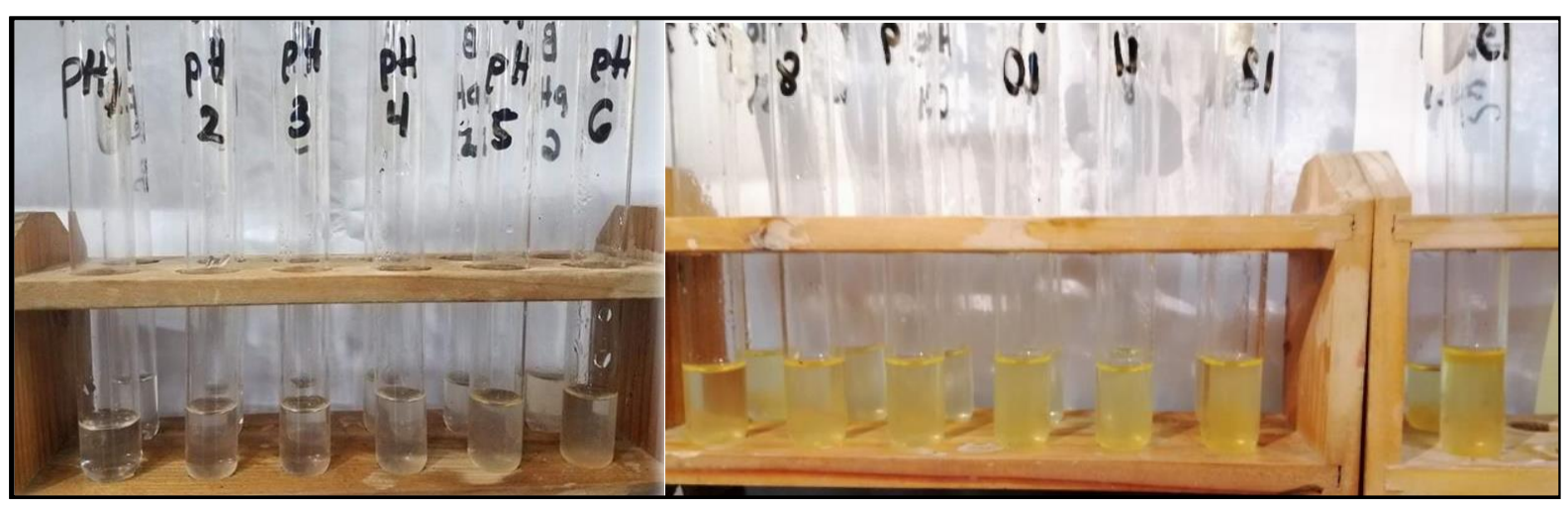

Figure 4. Color changes in tomato fruit extracts at $\mathrm{pH}$ 1-13

The color chart based on the color changes in Figures 2-4 is shown in Table 3 comparing the changes in color of the natural indicators from the commonly used laboratory indicators.

Table 3. Color chart: changes across pH levels of the natural and laboratory indicators

\begin{tabular}{|l|c|c|c|c|c|c|c|c|c|c|c|c|c|}
\hline \multirow{2}{*}{ Indicators } & \multicolumn{9}{|c|}{ pH Range } & $\mathbf{1 0}$ & $\mathbf{1 3}$ \\
\hline & $\mathbf{1}$ & $\mathbf{2}$ & $\mathbf{3}$ & $\mathbf{4}$ & $\mathbf{5}$ & $\mathbf{6}$ & $\mathbf{7}$ & $\mathbf{8}$ & $\mathbf{9}$ & $\mathbf{1 0}$ & $\mathbf{1 1}$ & $\mathbf{1 2}$ & $\mathbf{1 3}$ \\
\hline 1. Cassava, with water only & & & & & & & & & & & & & \\
\hline 2. Piti-piti, with water only & & & & & & & & & & & & & \\
\hline 3. Tomato, with water only & & & & & & & & & & & & & \\
\hline 4. blue litmus paper & & & & & & & & & & & & & \\
\hline 5. red litmus paper & & & & & & & & & & & & & \\
\hline 6. phenolphthalein & & & & & & & & & & & & & \\
\hline
\end{tabular}

The color of cassava leaf extracts exposed to an acid at $\mathrm{pH} 1$ is coherent with the characteristic color (colorless). This color drastically becomes green at $\mathrm{pH} 2$ until $\mathrm{pH} 7$ and that the latter $\mathrm{pH}$ also corresponds to the characteristic color (dark green). At pH 8 to 13, the colors become lighter to green and yellow green, and finally dirty white. The different shades of green in the color change can be attributed to the pigment called chlorophyll $a$ and $b$, one of the main pigments in cassava leaves (Nuwamanya et al., 2014). Chlorophyll $a$ has intense blue-green color while $b$ has yellow-green color (Paciulli et al., 2017) and these colors change to grey-green and yellow, respectively in acidic environments (Gibson, 2018), where the green coloration agrees well with 
the results of the present experiment. In alkaline environments, the pigments become green and even brighter green (Gibson, 2018), contrasting the colors at pH 12 and 13, which the latter also does not coincide with the characteristic color (dark green). This suggests that the leaf extracts can be used for identifying acids but less for bases; however, this result contrasted the study of Vedad (2006) that found out that the leaf extracts indicated the ability in identifying bases rather than acids. Significant changes in color occur when the chlorophyll pigments in the leaves when exposed to acids rather than bases where they retain their green coloration (Gibson, 2018).

Piti-piti flower extracts produced almost different colors across $\mathrm{pH}$ levels. The color changes were described as dark pink to light pink, then to dark green to light green and yellow, and lastly to light yellow. These color changes can be attributed to the presence of anthocyanins that give pitipiti its blue-purple flowers (Putri et al., 2019). Anthocyanins become intense red, purplish, and green/yellow colors when exposed to acidic, neutral, and basic solutions (Ibrahim et al., 2011). The different color changes might be attributed to the stability of anthocyanin pigments greatly affected by $\mathrm{pH}$, forming new derivative compounds (Putri et al., 2019). There is consistency between the identification of the characteristic color of acid (pink) and neutral (dark green) but not at $\mathrm{pH} 13$ condition (dark green). This result also contrasted the finding of Ibrahim et al. (2011) and Putri et al. (2019) that stated that strong bases have yellow color.

The results of the tomato extract indicator showed coherence between the characteristic acidbase colors and $\mathrm{pH}$ value-specific colors: colorless at $\mathrm{pH} 1-6$, and yellow at $\mathrm{pH} 7$ to 12 . These colors can be attributed to the carotenoid composition of tomatoes (Martí, 2016). Carotenoids are colored red, orange or yellow (Andrés-Bello et al., 2013) and become less intense color under acidic conditions and more intense ones under basic conditions, which is the same trend found out by literature (Mebane and Rybolt, 1985). The color changes in the present experiment are also comparable with the read literature, except for $\mathrm{pH}$ 13. The present study found out the color changed to light green at $\mathrm{pH} 13$ while literature stated yellow at the same $\mathrm{pH}$ (Mebane and Rybolt, 1985).

In general, color changes occurred when the indicator was mixed with the acid or base, as the plants extracts used in the experiment have pigments (particularly chlorophyll, anthocyanins, and carotenoids) that change color when reacted with certain substances (Andrés-Bello et al., 2013; Bhise et al., 2014). However, there is inconsistency in the color changes once pH levels approach the strongly basic end, not coinciding with the results of Vedad (2006), Putri et al. (2019), and Mebane and Rybolt (1985) for cassava leaves, piti-piti flowers, and tomato fruits, respectively. The inconsistency in the results may be attributed to the use of raw plant extracts containing not only the characteristic pigments but also other pigments, such as the presence of carotenoids and anthocyanins in cassava leaves (Suresh et al., 2011; Nuwamanya et al., 2014), which may have interfered the changing of colors. Additionally, errors may have occurred during the conduct of the experiment, particularly on the preparation of standard basic solutions because inconsistency in the results occurs in $\mathrm{pH}$ 13. These factors should be considered in the enhancement of the home-based experiment to yield accurate and reliable results.

The acid-base indicators were then tested to common household materials found at home. The results of the testing are reflected in Table 4. 
Table 4. Results of testing the indicators to common household materials

\begin{tabular}{|c|c|c|c|c|c|c|}
\hline \multirow[b]{2}{*}{ Substances } & \multicolumn{2}{|c|}{ Cassava leaves } & \multicolumn{2}{|c|}{ Piti-piti flowers } & \multicolumn{2}{|c|}{ Tomato fruits } \\
\hline & pH eq. ${ }^{1}$ & $\begin{array}{c}\mathrm{pH} \\
\text { standard }^{2}\end{array}$ & pH eq. ${ }^{1}$ & $\begin{array}{c}\mathrm{pH} \\
\text { standard }\end{array}$ & pH eq. ${ }^{1}$ & $\begin{array}{c}\mathrm{pH} \\
\text { standard }\end{array}$ \\
\hline baby powder & & & $7-8$ & 8.5-9.5 & & \\
\hline baking soda & 8 & 8 & $10-11$ & 8 & & \\
\hline bleach & 13 & 13 & & & $10-12$ & 13 \\
\hline calamansi & $1-2$ & 2 & $2-3$ & 2 & & \\
\hline detergent solution & 13 & 10 & & & $10-12$ 口 & 10 \\
\hline muriatic acid & $1-2$ & 1 & & & $\nabla$ & 1 \\
\hline shampoo & & & 3-4 & $7-10$ & $7-9$ & $7-10$ \\
\hline soda drink & & & $3-4$ & $3-4$ & $\nabla$ & 3-4 \\
\hline vinegar & $1-2$ & 2 & $3-4$ & 2 & $\nabla$ & 2 \\
\hline Percent Correct $^{3}$ & & $\%$ & 67 & & 100 & \\
\hline
\end{tabular}

${ }_{1}^{1} \mathrm{pH}$ value based on the color chart derived from the experiment

2 pH value based on "pH of common substances" by EPA (2015)

3 The pH eq. is marked with a check when it is equal to $\mathrm{pH}$ standard \pm 1 . Percent match $=$ correct items $/ 6 \mathrm{x}$ 100

Results show that all pH values were correctly matched (100\% accuracy) when the tomato fruit extracts were used to test the household materials. Five out of six $\mathrm{pH}$ values (83\% accuracy) were correctly matched for cassava leaf extracts while 4 out 6 (67\% accuracy) were matched for pitipiti flower extracts. The results of this testing unveiled the effectiveness of less color changes brought about by the indicator like the colors of the tomato indicator. This is in contrast with cassava leaf and piti-piti flower extracts, which have many color changes that led to incorrect identification of $\mathrm{pH}$ values of the household materials.

Opportunities from the Experiment. From doing the experiment, the teacher participants articulated that students could be able to derive positive things from conducting the home-based experiments. They highlighted three opportunities, namely (1) improved learning, (2) skills application, and (3) values development.

Improved Learning. Teachers emphasized that students can improve their learning when doing the home-based experiment because they did it on their own. By doing the experiment, they discover new things about acids and bases and realize that there are so many indicators that can be found in their backyards and the community in general. Most importantly, they can be able to understand the concepts that they have not comprehended well before. The use of hands-on activities and contextualized materials lead to enhanced learning in Chemistry (Rivera and Sanchez, 2020; Ott et al., 2018).

Skills Application. Moreover, teachers also noted that through the home-based activity, the students are given the chance to apply their skills in the experiment. During the process, they will be able to observe and measure as well as manipulate tools and mix substances. Resourcefulness becomes a skill as they find materials to do the experiment. Basic and integrated process skills can be developed during process-oriented activities and student-oriented tasks in Chemistry (Akani, 2015).

Values Development. According to the teachers, the home-based lab experiment is gearing towards holistic development as students develop values based on what they experience during the experimentation. By doing the hands-on activity, the students will develop appreciation of the concepts behind the topic. Their curiosity will spark and this becomes a springboard for them to make more environmentally and economically friendly products. They will also have fun while 
they manage their time and resources to accomplish the task. Students are satisfied with homebased experiments as they increase their connection to real-life, providing the conditions essential for improved students' interest and appreciation in Chemistry (Gendjova, 2007).

Challenges encountered during the Experimentation and Ways of addressing them. The teachers encountered problems during the conduct of the experiments, and these will be some of the challenges that students can encounter while doing the experiment. These challenges include (1) Unavailability of materials, (2) Safety concerns, (3) Time allotment, and (4) Process-related issues.

Unavailability of Materials. As a home-based task, teachers thought immediately of the materials that will be used in the activity. The materials may not be readily available in the students' homes and some of the materials such as $\mathrm{HCl}$ and $\mathrm{NaOCl}$ need to be bought outside. With this in mind, teachers think of ways how to address these problems. They suggested that the science teacher must indicate alternatives in the worksheet so that students can still use other materials. Alternative materials such as common household materials can be used in lieu of standard apparatus and equipment to let learning at home proceed (Andrews et al., 2020).

Safety Concerns. Aside from the materials needed, teachers also mentioned that safety should be practiced at all time during the experiment. They talked about the experimentation space, the area where students will conduct the experiment, especially those living in close-tight residential areas. They also raised concerns about the hazards of the chemicals and the accidents that may occur. They recommended that the science teacher should indicate the safety notes in the worksheet and use safety household materials (Andrews et al., 2020).

Time Allotment. The teachers also noted that the time allotted to the experimentation must be considered in the planning of the lab activity. Since the home-based activity is intended for independent learning, then the time allotted to do the experiment is not enough because of the many processes included in the activity. Therefore, they suggested that the worksheet must be given ahead so that the student can read and devise a plan how to go about the experiment as time management is essential before and during lab experiments (Erdemir and Tomar, 2019).

Process-related Issues. The teachers stated that some processes in the experiment were challenging aspects of the home-based activity. These processes included extraction and color identification. The former was due to the longer time needed while the latter was due to difficulty in identifying the colors. Though, they addressed these challenges by using a lot of the indicator to yield greater amount of extract and a color scheme from the Internet and match the colors observed. These issues may be addressed by contacting the science teacher and/or asking help from adults at home to help in the process such as extraction (Neves et al., 2017).

Implications for Use in Remote Teaching. Results of this study give insights on remote learning.

Formulate a home-based activity that targets important competencies. As the education department modified the curriculum, science teachers should think first of the most essential competencies that could be translated into an experiment that can be done at home. The at-home activities must target not only the concepts and process skills but also the values and attitudes so that the students can appreciate the things they do at home. Hence, opportunities for holistic development are possible for the home-based activities.

Use common household materials and provide alternatives to these materials if not available. As students do the experiment at home, they will prepare and procure the materials needed. With this, teachers must consider the availability of materials at home like the common household materials and tools that can be readily available. If in case the household materials are not available, then the teachers must indicate in the worksheet some alternative materials to help 
students find appropriate materials. Therefore, the home-based activity utilizes materials readily available at home and in the community.

Strengthen home-school collaboration. Due to remote learning, the teaching-learning process has been shifted from the classroom to students' homes. As such, teachers must work with the parents in helping and monitoring the students in their activities, including the Chemistry at-home activities. Adult supervision is required for these activities. Therefore, parents can oversee the processes and may communicate with the teachers when necessary.

Use safe materials and conduct the experiment with utmost safety. Not only alternatives are important considerations in material selection but also the safe and non-hazardous nature of materials. Safety should be observed throughout the experimentation; hence, teachers must indicate the safety notes for each step in the worksheet. In this way, students and parents will be cautioned to do the step with care and safety.

\section{CONCLUSIONS}

The home-based laboratory experiment on natural acid-base indicators is feasible to be conducted by students as evaluated by teachers, however, accuracy of the results may be compromised due to different contexts of conducting the at-home experiment. Nevertheless, the activity can give opportunities for improved learning, skills development, values integration, and satisfaction to the students.

It is recommended that the home-based experiment be enhanced to incorporate the errors and other factors that have affected the inconsistency of the results to the published data. Moreover, it is highly suggested that teachers always consider resource availability, adult supervision, and safety concerns as well as home-school collaboration when planning, implementing, and assessing home-based experiments. Furthermore, it is proposed that future directions include testing the home-based experiment to a bigger sample, incorporating the views and experiences of parents concerning home-based experiments, and investigating the sustainability of these experiments.

\section{REFERENCES}

Akani O. Laboratory teaching: implication on students' achievement in chemistry in secondary schools in Ebonyi State of Nigeria. J Educ Prac. 2015; 6(3):206-213. https://eric.ed.gov/?id=EJ1081346

Andrés-Bello A, Barreto-Palacios V, García-Segovia P, Mir-Bel J, Martínez-Monzo J. Effect of pH on color and texture of food products. Food Eng Rev. 2013 May; 5:158-170. https://doi.org/10.1007/s12393-013-9067-2

Andrews JL, de Los Rios JP, Rayaluru M, Lee S, Mai L, Schusser A, Mak, CH. Experimenting with athome general chemistry laboratories during the COVID-19 pandemic. J Chem Educ. 2020 June; 97(7):1887-1894. https://doi.org/10.1021/acs.jchemed.0c00483

Bhise SH, Shinde, NG, Surve, BS, Pimpodkar NV, Shikalgar SS. Acalypha wilkesiana as natural pH indicator. Int J Nat Prod Res. 2014 Mar; 4(1):33-35. https://www.researchgate.net/publication/262301360 Acalypha wilkesiana as Natural pH In dicator 
Caruana DJ, Salzmann CG, Sella A. Practical science at home in a pandemic world. Nat Chem. 2020 Aug; 12:780-783. https://doi.org/10.1038/s41557-020-0543-z

Environmental Protection Agency. $\mathrm{pH}$ of common substances. EPA. 2015: https://www.epa.gov/sites/production/files/2015-10/documents/1622624.pdf

Erdemir M, Tomar H. The influence of time management behaviours before starting general physics laboratory-I experiments on academic achievement in the course. Cypriot J Educ Sci. 2019 Sept; 14(3):457-470. . https://doi.org/10.18844/cjes.v14i3.4133

Gendjova A. Enhancing students' interest in chemistry by home experiments. J Baltic Sci Educ. 2007; 6(3):5-15. http://oaji.net/articles/2014/987-1404288446.pdf

Gibson M. Food science and the culinary arts. Cambridge: Academic Press: 2018

Ibrahim UK, Muhammad II, Salleh RM. The effect of $\mathrm{pH}$ on color behavior of Brassica oleracea anthocyanin. J Appl Sci. 2011; 11:2406-2410. https://doi.org/10.3923/jas.2011.2406.2410

Irwanto, Rohaeti E, Widjajanti E, Suyanta. Students' science process skill and analytical thinking ability in chemistry learning. AIP Conf Proceed. 2017 Aug; 1868. https://doi.org/10.1063/1.4995100

Mapa A, Azucena E, Fidelino T, Rabago, L. VP science and technology: Laboratory manual and workbook in chemistry. Revised ed. Quezon City: Vibal Publishing House, Inc.: 1997

Martí R, Roselló S, Cebolla-Cornejo J. Tomato as a source of carotenoids and polyphenols targeted to cancer prevention. Cancers. 2016 Jun; 8:58. https://doi.org/10.3390/cancers8060058

Mebane RC, Rybolt TR. Edible acid-base indicators. J Chem Educ. 1985 Apr; 62(4):285. https://doi.org/10.1021/ed062p285

Neves BS, Altermann C, Gonçalves R, Lara MV, Mello-Carpes PB. Home-based vs. laboratory-based practical activities in the learning of human physiology: the perception of students. Adv Physiol Educ. 2017 Jan; 41(1):89-93. https://doi.org/10.1152/advan.00018.2016

Nuwamanya E, Rubaihayo PR, Mukasa S, Kyamanywa S, Hawumba J, Baguma Y. Influence of spectral properties of cassava leaf development and metabolism. Afr J Biotechnol. 2014 Feb; 13:834-843. https://doi.org/10.5897/AJB2013.12795

Okoduwa SIR, Mbora LO, Adu ME, Adeyi AA. Comparative analysis of the properties of acid-base indicator of rose (Rosa setigera), allamanda (Allamanda cathartica), and hibiscus (Hibiscus rosasinensis) flowers. Biochem Res Int. 2015 Dec; Article 381721. https://doi.org/10.1155/2015/381721

Ott LE, Carpenter TS, Hamilton DS, LaCourse, WR. Discovery learning: development of a unique active learning environment for introductory chemistry. J Schol Teach Learn. 2018 Dec; 18(4):161-180. https://doi.org/10.14434/josotl.v18i4.23112

Paciulli M, Palermo M, Chiavaro E, Pellegrini N. Chlorophylls and color changes in cooked vegetables. In Yahia EM, ed. Fruits and vegetable phytochemicals: chemistry and human health. 2nd Ed. John Wiley \& Sons, Ltd: 2017. https://doi.org/10.1002/9781119158042.ch31

Putri OD, Pertiwi DW, Widjajani BW. Utilization of anthocyanin extracted from pletekan (Ruellia tuberosa L.) in determination soil pH. J Trop Horticul. 2019 Oct; 2(2):34-37. http://dx.doi.org/10.33089/ithort.v2i2.19 
Rivera GM, Sanchez JMP. Use of contextualized instructional materials: the case of teaching gas laws in a public uptown high school. Orbital: Electron J Chem. 2020 Dec; 12(4):276-281. http://dx.doi.org/10.17807/orbital.v12i4.1526

Safitri E, Afifah N, Khairi, Nazaruddin, Susilawati, Sani ND. Ruellia tuberosa L anthocyanin extract as a pH sensitive substance. IOP Conf Ser: Earth Environ Sci. 2019 July; 364: 012015. https://iopscience.iop.org/article/10.1088/1755-1315/364/1/012015

Suresh R, Saravanakumar M, Suganyadevi P. Anthocyanins from Indian cassava (Manihot esculenta Crantz) and its antioxidant properties. Int J Pharma Sci Res. 2011 Apr; 37:1819-1828. http://dx.doi.org/10.13040/IIPSR.0975-8232.2(7).1819-28

Vedad JR. Feasibility of cassava "Manihot esculenta" leaf extract as an acid-base indicator. STII. 2006; $1-3$ 